Article

\title{
Detection of $\beta$-Lactamase-Producing Enterococcus faecalis and Vancomycin-Resistant Enterococcus faecium Isolates in Human Invasive Infections in the Public Hospital of Tandil, Argentina
}

\author{
Celia M. Schell ${ }^{1}$, Ana P. Tedim 2,3 (D), Mercedes Rodríguez-Baños ${ }^{2}$, Mónica D. Sparo ${ }^{1,4}$, \\ Sabina Lissarrague ${ }^{4}$, Juan A. Basualdo ${ }^{1}$ and Teresa M. Coque ${ }^{2,3,5, *}$
}

1 Centro Universitario de Estudios Microbiológicos y Parasitológicos (CUDEMyP), Centro Universidad Nacional de La Plata asociado a Comisión de Investigaciones Científicas (CIC), Facultad de Ciencias Médicas, Universidad Nacional de La Plata. Av. 60 y 120 s/n, 3er piso, CP 1900 La Plata, Buenos Aires, Argentina; schellcelia@gmail.com or schellcelia@med.unlp.edu.ar (C.M.S.); monicasparo@gmail.com (M.D.S.); jabasua@med.unlp.edu.ar (J.A.B.)

2 Servicio de Microbiología, Hospital Universitario Ramón y Cajal, Instituto Ramón y Cajal de Investigación Sanitaria (IRYCIS), Carretera de Colmenar, km. 9.1, Planta -1IZQ, 28034 Madrid, Spain; anspedrosa@gmail.com or assantos.iecscyl@saludcastillayleon.es (A.P.T.); merche1976es@yahoo.es (M.R.-B.)

3 Centros de Investigación Biomédica en Red de Epidemiología y Salud Pública (CIBER-ESP), Av. Monforte de Lemos, 3-5. Pabellón 11. Planta 0, 28029 Madrid, Spain

4 Laboratorio de Microbiología Clínica, Hospital Municipal Ramón Santamarina, Gral. Paz 1406, B7000 Tandil, Buenos Aires, Argentina; sabinalissarrague@gmail.com

5 Unidad de Resistencia a Antibióticos y Virulencia Bacteriana asociada al Consejo Superior de Investigaciones Científicas (CSIC), 28006 Madrid, Spain

* Correspondence: mariateresa.coque@salud.madrid.org or teresacoque@gmail.com; Tel.: +34-913-368-330

Received: 29 January 2020; Accepted: 18 February 2020; Published: 20 February 2020

\begin{abstract}
The study's aim was to analyze the population structure of enterococci causing human invasive infections in a medium-sized Argentinian Hospital coincidental with a 5 year-period of increased recovery of antibiotic resistant enterococci (2010-2014). Species identification (biochemical testing/MALDI-TOF-MS), antimicrobial susceptibility (disk-diffusion) and clonal relatedness (PFGE/MLST/BAPS) were determined according to standard guidelines. $\beta$-lactamase production was determined by a nitrocefin test and confirmed by PCR/sequencing. The isolates were identified as Enterococcus faecalis and Enterococcus faecium at a 2:1 ratio. Most of the E. faecalis isolates, grouped in 25 PFGE-types (ST9/ST179/ST236/ST281/ST388/ST604/ST720), were resistant to high-levels (HLR) of gentamicin/streptomycin. A ST9 clone (bla $/$ HLR-gentamicin) was detected in patients of different wards during 2014. E. faecium isolates were grouped in 10 PFGE-types (ST25/ST18/ST19/ST52/ST792), with a low rate of ampicillin resistance. Five vancomycin-resistant E. faecium, three vanA (ST792/ST25) and two vanB (ST25) were detected. The ST25 clone carried either vanA or vanB. The recovery of a bla ${ }^{+}-S T 9-E$. faecalis clone similar to that described in the late 1980s in Argentina suggests the possibility of a local hidden reservoir. These results reflect the relevance of local epidemiology in understanding the population structure of enterococci as well as the emergence and spread of antimicrobial resistance in predominant enterococcal clonal lineages.
\end{abstract}

Keywords: Enterococcus faecalis; Enterococcus faecium; invasive infections; antibiotic resistance; VRE; $b l a^{+}$ 


\section{Introduction}

Enterococcus faecalis and Enterococcus faecium became two of the most important nosocomial pathogens in recent decades [1]. The treatment of severe enterococcal infections is frequently impaired by the intrinsic and/or acquired resistance to first-line antibiotics, namely, those active against the cell wall ( $\beta$-lactam or glycopeptides) and aminoglycosides, which combine to achieve a bactericidal effect [1]. Resistance to these therapeutic choices has been extensively reported in Western countries [2,3] but information from other locations including Argentina is still scarce and comes from studies focused on glycopeptide resistance [4,5]; early descriptions of emerging mechanisms of resistance ( $\beta$-lactamase production) [6]; or cross-sectional surveillance studies which only include a few isolates from different geographical locations (https://resistancemap.cddep.org/, [7]).

Enterococci are intrinsically resistant to some $\beta$-lactam antibiotics such as cephalosporins and carbapenems but resistance to penicillin is acquired either by mutations in penicillin binding proteins (PBPs) or, less frequently, by the production of a $\beta$-lactamase [8]. Resistance to aminopenicillins is very common in E. faecium and is mostly due to mutations in the PBP5 [9], and sporadically, to the production of $\beta$-lactamase [10]. Although most E. faecalis isolates are susceptible to penicillin, penicillin-resistant and ampicillin-susceptible E. faecalis (PRASEF) have been reported since the late 1980s in different countries including Argentina [11,12]. To date, PRASEF can result from the production of $\beta$-lactamase or mutations in the PBP4 [13]. Resistance to glycopeptides is mediated by a plethora of genetic determinants, with genotypes vanA (Tn1546) and vanB (Tn5382/Tn1547) being the most predominant [3]. The first vancomycin-resistant enterococci (VRE) reported in Latin-America was isolated in Mendoza, Argentina, in 1996 from a 7-year old male patient treated with different antibiotics and was identified as E. faecium (vanA) [14]. After this sporadic case, E. faecium harbouring vanA or vanB in colonized or infected patients were detected in several Argentinean hospitals [4,5,15]. Most of these VRE were E. faecium (vanA) [3,16] and, sporadically, E. faecalis and Enterococcus gallinarum [3,17].

High-level resistance (HLR) to gentamicin in enterococci was first described in 1979 in France and by the late 1980s, in different countries including Argentina which is often associated with E. faecalis $\beta$-lactamase producers [11,12]. Recent data at the CDDEP site (https://resistancemap.cddep.org/) revealed that Argentinian E. faecium invasive isolates are commonly resistant to ampicillin $(>75 \%-80 \%)$ and vancomycin $(60 \%-75 \%)$ while E. faecalis invasive isolates are rarely resistant to cell-wall active antibiotics. HLR to gentamicin is often observed in both species $(60 \%$ and $30 \%$, respectively).

Most E. faecium and E. faecalis clinical isolates belong to a few sequence types (STs), namely ST6, ST9, ST16 and ST87 for E. faecalis, and ST17, ST18 and ST78 for E. faecium, some of them overrepresented in different geographical areas [2,18]. For E. faecium, population structure often combines MLST and Bayesian analysis of the population structure (BAPS). Hospital isolates often cluster in BAPS subgroups 2.1a (ST117, ST203 and ST80) and 3.3a (ST18 and ST17) while community-based isolates belong to BAPS subgroups 1.2 and 3.3b $[18,19]$. These predominant STs are also called “high-risk clonal complexes" [20].

The aim of this study was to characterize the E. faecalis and E. faecium from human invasive infections in the Public Hospital of Tandil, Argentina, a medium-sized hospital covering urban and rural human populations. The interest of the study lies in its value for describing the population structure of enterococci during a period of increasing recovery of multidrug-resistant (MDR) isolates in a geographical area with low prevalence of enterococci resistance to first-line antibiotics but where emblematic mechanisms of resistance were detected early.

\section{Results}

\subsection{Epidemiological Background of the Strains Isolated from Human Invasive Infections in Hospital Ramón Santamarina (HRS).}

Epidemiological data of the 63 Enterococcus spp. strains (44 E. faecalis and 19 E. faecium) analysed in this study are shown in Tables 1 and 2. Both E. faecalis and E. faecium were isolated from seven 
samples (three peritoneal fluids, two liver abscesses, one abdominal fluid, and one synovial fluid). The age of the patients ranged from 16 to 92 years $(59 \pm 18.8-y, 70 \%>50$ years old), most of them with an underlying disease (49\%) and a history of antibiotic exposure (80\%), mainly to ciprofloxacin (23.6\%), cephalexin $(18.2 \%)$ and ceftriaxone $(14.5 \%)$. The mortality rate in this series was $27.3 \%$ (Table S1).

Table 1. Relevant characteristics of the $44 \mathrm{E}$. faecalis strains isolated from human invasive infections at the Hospital Ramón Santamarina (HRS), Buenos Aires (Argentina).

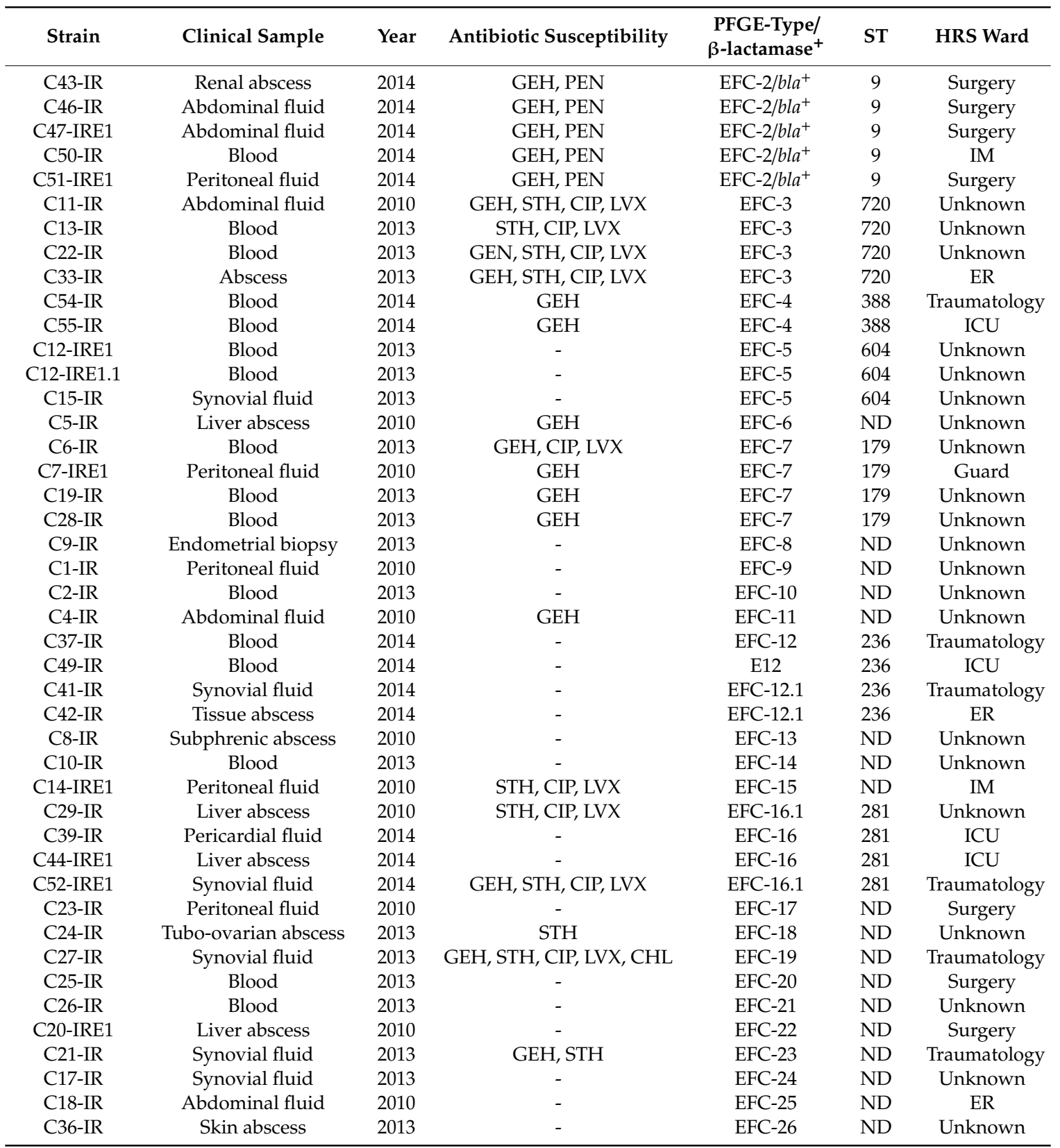

Abbreviations: ST, Sequence type; CC, Clonal Complex; ND, Not determined; GEH: gentamicin; STH: streptomycin; PEN: penicillin; CIP: ciprofloxacin; LVX: levofloxacin; CHL: chloramphenicol; IM, Internal medicine; ER, Emergency room; ICU, Intensive care unit. 
Table 2. Relevant characteristics of the 19 E. faecium strains isolated from human invasive infections at the HRS, Buenos Aires (Argentina).

\begin{tabular}{|c|c|c|c|c|c|c|c|c|}
\hline Strain & Clinical Sample & Year & Antibiotic Susceptibility & van Genotype & PFGE-Type & ST & BAPS & HRS Ward \\
\hline C47-IRE2 & Abdominal fluid & 2014 & VAN, $\mathrm{Q} / \mathrm{D}, \mathrm{PEN}$ & $\operatorname{van} B$ & EFM-1 & 25 & 2.3 & Surgery \\
\hline C48-IR & Blood & 2014 & VAN, TEC, Q/D, PEN & $\operatorname{van} A$ & EFM-1 & 25 & 2.3 & Surgery \\
\hline C38-IR & Blood & 2014 & - & - & EFM-1 & 25 & 2.3 & Traumatology \\
\hline C30-IR & Blood & 2013 & VAN & van $B$ & EFM-1 & 25 & 2.3 & $\mathrm{ICU}$ \\
\hline C31-IR & Abdominal fluid & 2010 & LVX, PEN, AMP & - & EFM-2 & ND & ND & ER \\
\hline C32-IR & Intravesicular fluid & 2010 & - & - & EFM-2.1 & ND & ND & Unknow \\
\hline C34-IR & Sinovial fluid & 2013 & PEN & - & EFM-2 & ND & ND & Unknow \\
\hline C45-IR & Blood & 2014 & PEN, SAM & - & EFM-3 & 18 & 3.3 & Traumatology \\
\hline C52-IRE2 & Sinovial fluid & 2014 & PEN, AMP, SAM & - & EFM-3 & 18 & 3.3 & Traumatology \\
\hline C16-IR & Blood & 2013 & PEN & - & EFM-4 & ND & ND & ICU \\
\hline C20-IRE2 & Liver abscess & 2013 & - & - & EFM-4 & 52 & 7 & Surgery \\
\hline C35-IR & Peritoneal fluid & 2010 & - & - & EFM-4 & 52 & 7 & ER \\
\hline C3-IR & Blood & 2013 & - & - & EFM-5 & ND & ND & Unknow \\
\hline C7-IRE2 & Peritoneal fluid & 2010 & GEH, Q/D & - & EFM-5 & ND & ND & ER \\
\hline C14-IRE2 & Peritoneal fluid & 2010 & - & - & EFM-6 & ND & ND & $\mathrm{IM}$ \\
\hline C53-IR & Abdominal abscess & 2014 & VAN, TEC, GEH, CIP, LVX, PEN, AMP, SAM & $\operatorname{van} A$ & EFM-7 & 792 & 3.1 & ICU \\
\hline C40-IR & Blood & 2014 & STH, PEN, AMP, SAM & - & EFM-8 & 19 & 7 & Traumatology \\
\hline C44-IRE2 & Liver abscess & 2014 & VAN, TEC, LVX, CIP, PEN, AMP, SAM & $\operatorname{van} A$ & EFM-9 & 792 & 3.1 & ICU \\
\hline C51-IRE2 & Peritoneal fluid & 2014 & - & - & EFM-10 & ND & ND & Surgery \\
\hline
\end{tabular}

Abbreviations: ST, Sequence type; VAN: vancomycin; TEC: teicoplanin; GEH: gentamicin; STH: streptomycin; PEN: penicillin; AMP: ampicillin; SAM: ampicillin/sulbactam; CIP: ciprofloxacin; LVX: levofloxacin; Q/D: quinupristin-dalfopristin; ND, Not determined; ICU, Intensive care unit; ER, Emergency room; IM, Internal medicine. 


\subsection{E. faecalis}

Approximately half of the E. faecalis isolates (47.7\%) were susceptible to all antibiotics tested (Figure 1). HLR to gentamicin $(43.2 \%)$, streptomycin $(22.7 \%)$ or both $(13.6 \%)$ and resistance to fluoroquinolones (20.4\%, ciprofloxacin and levofloxacin), penicillin (11.4\%) and chloramphenicol (2.3\%) were detected. The production of $\beta$-lactamase was inferred for the five PRASEF isolates based on the $5 \mathrm{~mm}$ increase in the inhibition diameter to ampicillin-sulbactam compared to ampicillin [21], a positive nitrocefin test and the identification of a class $A \beta$-lactamase gene conferring resistance to aminopenicillins (GenBank accession number U43087.1). None of these strains showed mutations in the PBP4 previously associated with possible penicillin resistance (data not shown). The PRASEF isolates exhibited the same PFGE-type, EFC-2, and were classified as ST9. The rest of the E. faecalis strains were grouped in 24 different PFGE-types. Besides EFC-2, the most common PFGE-types were EFC-7, EFC-16 and EFC-3 which correspond to ST179, ST281, and ST720, respectively. ST720 is a novel E. faecalis ST described here for the first time (Table 2).

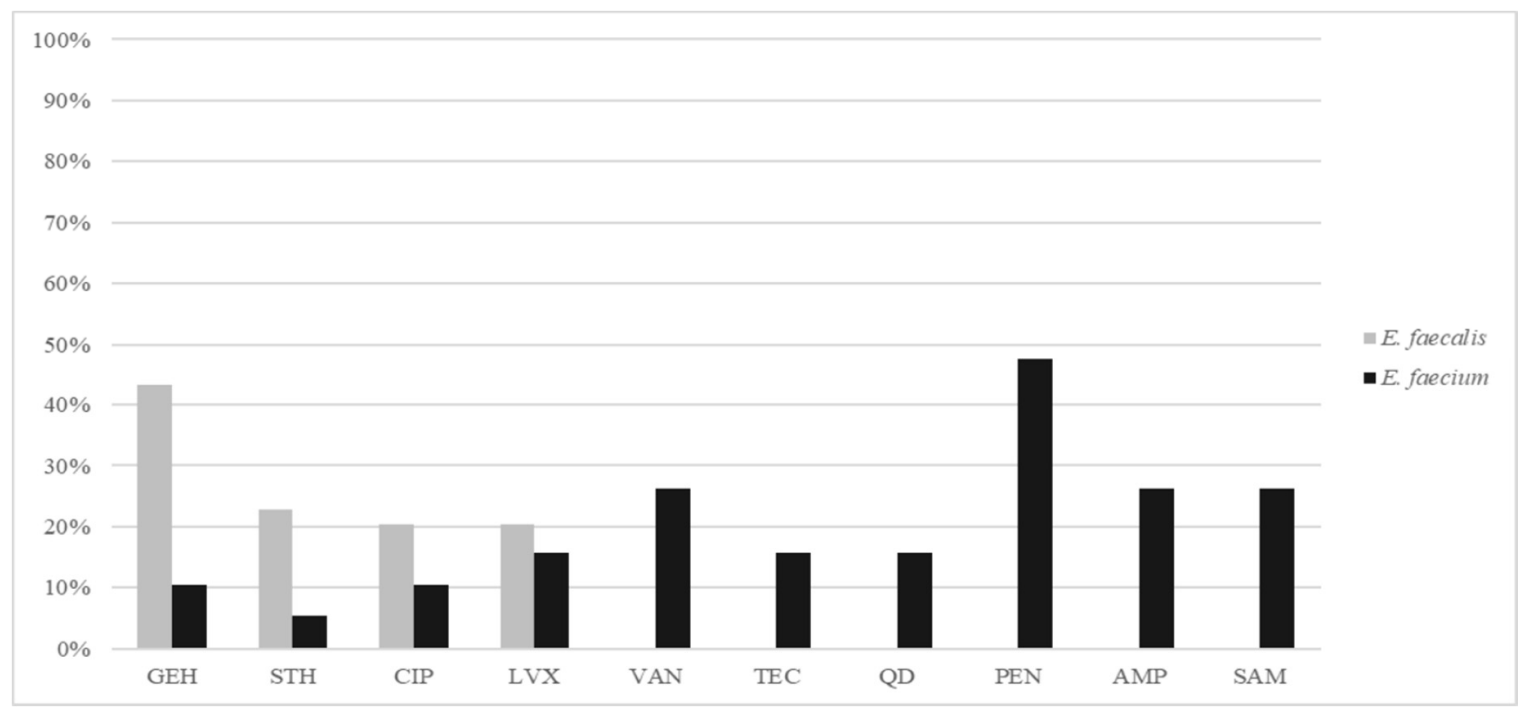

Figure 1. Percentage of antimicrobial resistance in E. faecalis and E. faecium strains isolated from invasive infections.

\subsection{E. faecium}

E. faecium isolates were resistant to penicillin (47.4\%), ampicillin and ampicillin/sulbactam, vancomycin (26.3\% each), teicoplanin, levofloxacin and quinupristin-dalfopristin ( $15.8 \%$ each), ciprofloxacin and high levels of gentamicin (10.5\%; Figure 1). Only one isolate showed HLR to streptomycin. All E. faecium strains were susceptible to linezolid, tigecycline and chloramphenicol. Three E. faecium strains were MDR according to Magiorakos et al. (phenotypic resistance to three or more antibiotic families) [22]. E. faecium strains were grouped in 10 different PFGE-types (Figure 2), the predominant ones being: EFM-1, EFM-2 and EFM-4. EFM-1 and EFM-4 belonged to ST25-BAPS 2.3 and ST52-BAPS 7, respectively. 


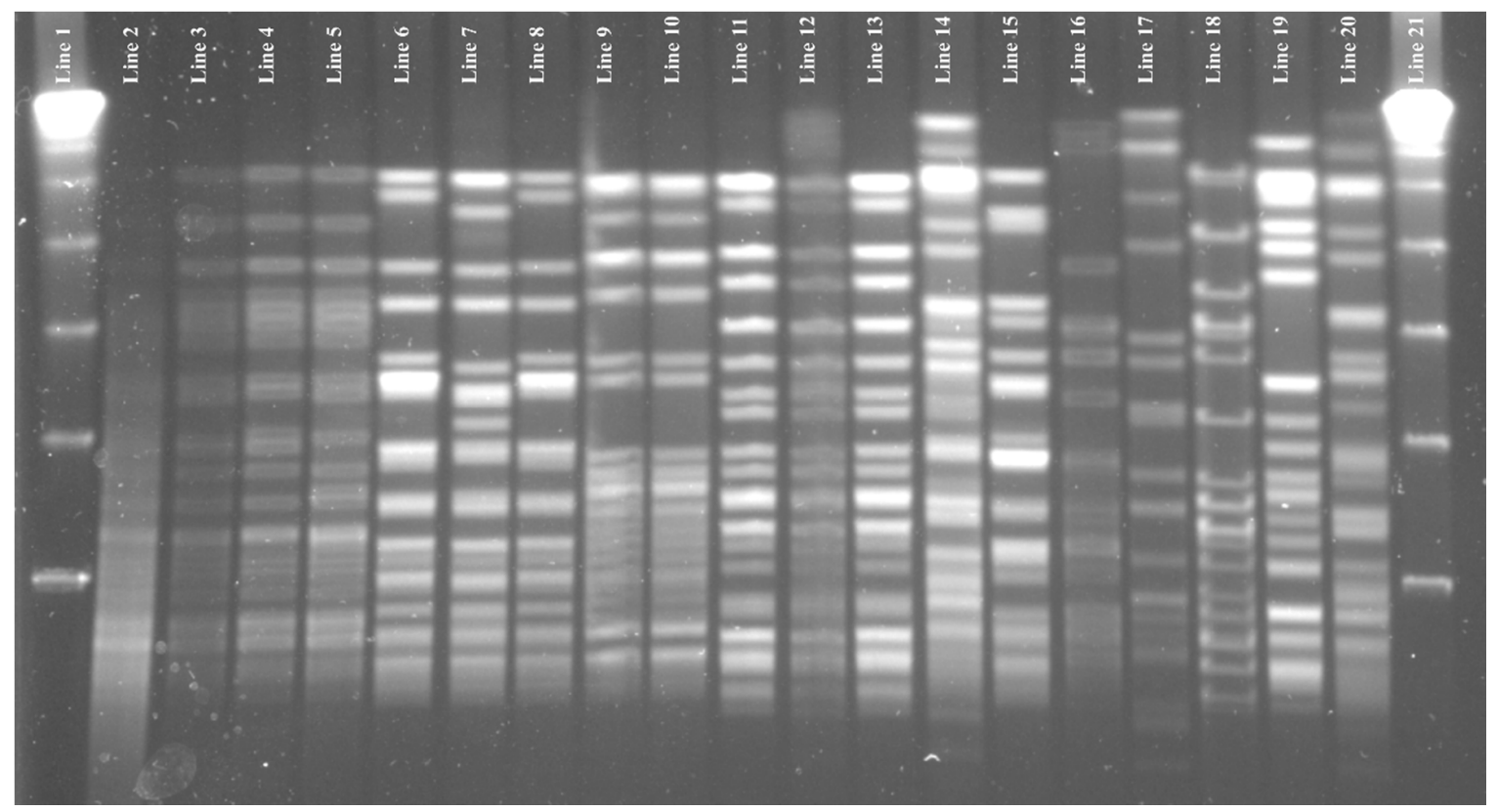

Figure 2. PFGE patterns of SmaI-digested genomic DNA of E. faecium strains analysed in this study. Line 1 to 21: $\lambda$, lambda ladder Marker. Line 2: C30-IRE1 van $B^{+}$; line 3: C38-IRE1; line 4: C47-IRE2 vanB ${ }^{+}$; line 5: C48-IRE1 van $A^{+}$; line 6: C31-IR; line 7: C32-IR; line 8: C34-IR; line 9: C45-IR; line 10: C52-IRE1; line 11: C16-IRE1; line 12: C20-IRE2; line 13: C35-IR; line 14: C7-IRE2; line 15: C14-IRE2; line 16: C40-IRE1; line 17: C44-IRE2 van ${ }^{+}$; line 18: C51-IRE2; line 19: C53-IR vanA ${ }^{+}$; line 20: C3-IR.

Five vancomycin-resistant $E$. faecium strains (three van $A$ and two van $B$ ) were detected in this study. Two vanA E. faecium isolates had different PFGE-types (EFM-7 and EFM-9) but both belonged to BAPS 3.1-ST792. The other vanA strain and the two vanB strains showed the same PFGE-type, EFM-1, and were identified as BAPS 2.3-ST25. The two vanB strains were isolated from blood and abdominal fluid samples of patients with documented bloodstream and intra-abdominal infections at the surgery and ICU wards in 2013 and 2014.

\section{Discussion}

This report documents the presence of relevant high-risk clonal complexes of E. faecalis and $E$. faecium [2], underrepresented in most of the studies in Western countries but able to acquire and disseminate resistant genes to first-line antibiotics.

Among E. faecalis, the ST9-PRASEF clone ( $b l a^{+} /$HLR-gentamicin) identified in this study represents one of the few bla $-E$. faecalis strains described to date, most of them documented in the late 1980s in the USA, Lebanon, Canada and Argentina [23]. The apparent relationship between the ST9-bla ${ }^{+}$ isolates described here and those reported in another hospital of Buenos Aires in 1989, both showing HLR to gentamicin, suggest that this clone could have been circulating in our area since the late 1980s. Geographical endemicity of E. faecalis with infrequent mechanisms of resistance, such as the production of $\beta$-lactamase or resistance to vancomycin, have previously been described in specific regions of the USA, either due to an epidemic clone (ST6-bla ) [11,23] or an epidemic plasmid (Inc18-vanA) [24]. To date, it is not well understood why these antibiotic resistant strains remain apparently confined to specific regions. The presence of other E. faecalis such as ST179, ST388 and ST720 (HLR-gentamicin) in more than one patient in different wards reflects the transmissibility of several clones in our hospital.

Similarly, the E. faecium strains did not belong to clonal groups predominant in most hospitals as BAPS subgroups 3.3a (ST18 and ST17) or 2.1a (ST117, ST203 and ST80) $[18,19,25,26]$. Instead, it is of note that the detection of clones of other phylogenomic groups, often associated with animals and able to acquire different resistance traits such as BAPS 3.1-ST792 (2 vanA) or BAPS 2.3-ST25 ( 2 van $B$ and 1 vanA) $[18,19,27]$. This clonal diversity explains the low occurrence of ampicillin resistant 
E. faecium found in our study in comparison with that reported in other series $(26.3 \%$ vs. $>85 \%)$ (https://resistancemap.cddep.org/CountryPage.php?countryId=65\&country=Argentina, $[16,17,28]$ ).

The diversity of E. faecalis and E. faecium able to acquire genes encoding HLR to gentamicin and streptomycin, some clones with zoonotic potential, might facilitate the spread of these genes between different hosts, as recently reported in our area $[19,25,28,29]$.

Despite the limited sample analysed, epidemiological data of this series, the E. faecalis:E. faecium prevalence ratio, the diversity of clinical presentations $[2,18,25]$, the age/sex of the patients and the risk factors for the acquisition of enterococcal infections $[18,30]$ were in agreement with other studies.

In summary, the epidemiology of enterococci in a medium-sized hospital in South America during a non-outbreak situation revealed interesting information for public health. The persistence of emblematic and unusual resistant clones such as E. faecalis ST9 (bla ${ }^{+}$, HLR-gentamicin) suggests the presence of hidden reservoirs for MDR E. faecalis in different geographical areas. Moreover, it highlights the importance of defining the population structure of enterococci in different locations in order to understand the influence of sociodemographic factors in the clonal diversity of enterococci and thus in the emergence and transmission of antimicrobial resistance.

\section{Materials and Methods}

\subsection{Epidemiological Data and Sampling of Enterococcus spp.}

We retrospectively analysed all Enterococcus spp. strains consecutively isolated from patients with clinically documented invasive infections who were hospitalized at the HRS between 2010 and 2014 . The HRS is a medium-sized hospital of 120 beds that provides specialized attention to a population size of $\sim 130,000$ habitants in the area of Buenos Aires (Argentina). More precisely, 41,000 individuals were attended to at the HRS during the period 2013-2014. After the study, only a few isolates resistant to first-line antibiotics were recorded (data not shown).

The samples analysed included blood $(n=22)$, abscess $(n=12)$, synovial fluid $(n=7)$, abdominal fluid $(n=6)$, peritoneal fluid $(n=6)$, intravesicular fluid $(n=1)$ and pericardial fluid $(n=1)$. One colony per morphology per patient was selected for further studies. All strains were identified with biochemical conventional tests [31] and confirmed by MALDI-TOF-MS (Bruker Daltonics, Bremen, Germany).

\subsection{Ethical Approval}

Patient records (underlying diseases, previous antimicrobial therapy, mortality, age and gender) were obtained in compliance with National Law No. 25.326 art. 11 of "Personal Data Protection" and National Law No. 26529/10 "Patient Rights, Clinical History and Informed Consent" of Argentina, in line with the Helsinki statement. A computerized data system was implemented at the HRS to optimize the management of information through the Integrated System of Argentinian Sanitary Information (SISA) in 2011. Due to the lack of this computerized data system, it was not possible to obtain all the data from the clinical history of some patients, especially those deceased.

\subsection{Antimicrobial Susceptibility}

Susceptibility to 13 antibiotics was determined by the disc diffusion method and using the ADAGIO ${ }^{\text {тм }}$ Automated System (Bio-Rad, Hercules, CA, USA) as described. The antibiotics tested included ampicillin $(10 \mu \mathrm{g})$, penicillin $(6 \mu \mathrm{g})$, ampicillin/sulbactam $(20 \mu \mathrm{g})$, chloramphenicol $(30 \mu \mathrm{g})$, vancomycin $(5 \mu \mathrm{g})$, teicoplanin $(30 \mu \mathrm{g})$, streptomycin $(300 \mu \mathrm{g})$, gentamicin $(120 \mu \mathrm{g})$, ciprofloxacin $(5 \mu \mathrm{g})$, levofloxacin $(5 \mu \mathrm{g})$, quinupristin-dalfopristin $(15 \mu \mathrm{g})$, linezolid $(30 \mu \mathrm{g})$ and tigecycline $(15 \mu \mathrm{g})$ (Bio-Rad, Hercules, CA, USA)]. Susceptibility to aminoglycosides, glycopeptides, quinolones and $\beta$-lactam antibiotics was also determined by an E-test (M.I.C. Evaluator ${ }^{\mathrm{TM}}$, OXOID, Basingstoke, UK). The methods and the interpretation of the results followed the CLSI guidelines [32]. Enterococcus faecalis ATCC 29212 and Staphylococcus aureus ATCC 25923 were used as control strains. 


\section{4. $\beta$-lactamase Production}

$\beta$-lactamase production was preliminary tested by the nitrocefin test (BD BBL, Franklin Lakes, NJ, USA), according to the manufacturer's instructions and further confirmed by PCR, and sequencing [33].

\subsection{Detection of van Genes}

van genes were detected by a multiplex PCR assay as previously described [34,35].

\subsection{Clonal Relatedness}

Clonal relatedness was preliminarily established by Pulsed Field Gel Electrophoresis (PFGE) as previously described [36,37]. A representative isolate per PFGE-type was further characterized by multi-locus sequence typing (MLST) according to PubMLST guidelines (http://pubmlst.org/) [38,39]. E. faecium MLST data were further characterized using by BAPS [18,19].

\subsection{Statistical Analysis}

Differences in the prevalence of tested features in E. faecalis and E. faecium strains were assessed by Chi-square and Fisher tests. A significance was established at $p<0.05$.

Supplementary Materials: The following are available online at http://www.mdpi.com/2076-0817/9/2/142/s1, Table S1: Relevant clinical epidemiological data included in this study.

Author Contributions: Conceptualization, T.M.C., M.D.S. and J.B.; methodology, C.M.S., A.P.T. and T.M.C.; formal analysis, C.M.S., A.P.T. and T.M.C.; investigation, C.M.S., A.P.T., M.R.-B. and S.L.; data curation, C.M.S. and A.P.T.; writing-original draft preparation, C.M.S. and A.P.T.; writing-review and editing, T.M.C., M.D.S. and J.A.B.; supervision, T.M.C., M.D.S. and J.A.B.; funding acquisition, C.M.S. and T.M.C. All authors have read and agreed to the published version of the manuscript.

Funding: C.M.S. was funded by the "Programa de Internacionalización de la Educación Superior y Cooperación Internacional (PIESCI). Secretaría de Políticas Universitarias. Ministerio de Educación y Deportes. República Argentina. Sexta convocatoria Movilidad a Madrid" (2015-2016) National University of La Plata. Buenos Aires, República Argentina (Subsidios para ayuda a Viajes y/o Estadías. Anexo 1, Resol. No 753/15 and PPID/M007-UNLP 2016). Laboratory expenses were funded by the grants to TMC (PI15/1307 and CIBERESP; CB06/02/0053), integrated in the Spanish 2013-2016 and 2017-2020 R+D+i State Plans and cofounded by Instituto de Salud Carlos III and the European Regional Development Fund (ERDF, "A way to achieve Europe").

Conflicts of Interest: The authors declare no conflict of interest.

\section{References}

1. Arias, C.A.; Murray, B.E. The rise of the Enterococcus: Beyond vancomycin resistance. Nat. Rev. Microbiol. 2012, 10, 266-278. [CrossRef] [PubMed]

2. Guzman Prieto, A.M.; van Schaik, W.; Rogers, M.R.C.; Coque, T.M.; Baquero, F.; Corander, J.; Willems, R.J.L. Global Emergence and Dissemination of Enterococci as Nosocomial Pathogens: Attack of the Clones? Front. Microbiol. 2016, 7, 788. [CrossRef] [PubMed]

3. Werner, G.; Coque, T.M.; Hammerum, A.M.; Hope, R.; Hryniewicz, W.; Johnson, A.; Klare, I.; Kristinsson, K.G.; Leclercq, R.; Lester, C.H.; et al. Emergence and spread of vancomycin resistance among enterococci in Europe. Euro Surveill. 2008, 13, 19046.

4. Togneri, A.; Corso, A.; González, J.; Lopardo, H.; Podestá, L.; Gagetti, P.; Peréz, M.; Rodríguez, V.; Rodríguez, M.; Ríos, L.; et al. Análisis clínico-epidemiológico de la portación intestinal de enterococos resistentes a vancomicina en una unidad de terapia intensiva. Rev. Argent. Microbiol. 2005, 37, $26-33$.

5. Lopardo, H.; Blanco, A.; Carbonaro, M.; Ruvinsky, S.; Andión, E.; Venuta, E.; Corso, A.; Gagetti, P.; Bologna, R. Impacto de 10 años de vigilancia de colonización con enterococos resistentes a vancomicina (ERV) en un hospital pediátrico de alta complejidad. Med. Infant. 2008, 1, 114-120.

6. Murray, B.E.; Mederski-Samaroj, B. Transferable beta-lactamase. A new mechanism for in vitro penicillin resistance in Streptococcus faecalis. J. Clin. Investig. 1983, 72, 1168-1171. [CrossRef] 
7. Pfaller, M.A.; Cormican, M.; Flamm, R.K.; Mendes, R.E.; Jones, R.N. Temporal and Geographic Variation in Antimicrobial Susceptibility and Resistance Patterns of Enterococci: Results from the SENTRY Antimicrobial Surveillance Program, 1997-2016. Open Forum Infect. Dis. 2019, 6, S54-S62. [CrossRef]

8. Rice, L.B.; Carias, L.L.; Rudin, S.; Hutton, R.; Marshall, S.; Hassan, M.; Josseaume, N.; Dubost, L.; Marie, A.; Arthur, M. Role of class A penicillin-binding proteins in the expression of beta-lactam resistance in Enterococcus faecium. J. Bacteriol. 2009, 191, 3649-3656. [CrossRef]

9. Novais, C.; Tedim, A.P.; Lanza, V.F.; Freitas, A.R.; Silveira, E.; Escada, R.; Roberts, A.P.; Al-Haroni, M.; Baquero, F.; Peixe, L.; et al. Co-diversification of Enterococcus faecium Core Genomes and PBP5: Evidences of pbp5 Horizontal Transfer. Front. Microbiol. 2016, 7, 1581. [CrossRef]

10. Sarti, M.; Campanile, F.; Sabia, C.; Santagati, M.; Gargiulo, R.; Stefani, S. Polyclonal diffusion of beta-lactamase-producing Enterococcus faecium. J. Clin. Microbiol. 2012, 50, 169-172. [CrossRef]

11. Murray, B.E. Beta-lactamase-producing enterococci. Antimicrob. Agents Chemother. 1992, 36, $2355-2359$. [CrossRef] [PubMed]

12. Hodel-Christian, S.L.; Murray, B.E. Comparison of the gentamicin resistance transposon Tn5281 with regions encoding gentamicin resistance in Enterococcus faecalis isolates from diverse geographic locations. Antimicrob. Agents Chemother. 1992, 36, 2259-2264. [CrossRef] [PubMed]

13. Conceição, N.; da Silva, L.E.P.; Darini, A.L.d.C.; Pitondo-Silva, A.; de Oliveira, A.G. Penicillin-resistant, ampicillin-susceptible Enterococcus faecalis of hospital origin: pbp4 gene polymorphism and genetic diversity. Infect. Genet. Evol. 2014, 28, 289-295. [CrossRef] [PubMed]

14. Marín, M.E.; Mera, J.R.; Arduino, R.C.; Correa, A.P.; Coque, T.M.; Stamboulian, D.; Murray, B.E. First report of vancomycin-resistant Enterococcus faecium isolated in Argentina. Clin. Infect. Dis. 1998, 26, 235-236. [CrossRef]

15. Corso, A.C.; Gagetti, P.S.; Rodríguez, M.M.; Melano, R.G.; Ceriana, P.G.; Faccone, D.F.; Galas, M.F. Molecular epidemiology of vancomycin-resistant Enterococcus faecium in Argentina. Int. J. Infect. Dis. 2007, 11, 69-75. [CrossRef]

16. Faccone, D.; Abel, F.; Lopez Ruitti, P.; Gagetti, P.; Corso, A. Diseminación de Enterococcus faecium con resistencia a glicopeptidos (VREFM) del complejo clonal 17 en Argentina. In Proceedings of the XII Congreso Argentino de Microbiología, VI Congreso de la Sociedad Argentina de Bacteriología, Micología y Parasitología Clínica-SADEBAC, I Congreso de Microbiología Agrícola y Ambiental, Buenos Aires, Argentina, 17-20 Octubre 2010.

17. Corso, A.; Faccone, D.; Gagetti, P.; Togneri, A.; Lopardo, H.; Melano, R.; Rodríguez, V.; Rodriguez, M.; Galas, M. First report of VanA Enterococcus gallinarum dissemination within an intensive care unit in Argentina. Int. J. Antimicrob. Agents 2005, 25, 51-56. [CrossRef]

18. Tedim, A.P.; Ruiz-Garbajosa, P.; Corander, J.; Rodríguez, C.M.; Cantón, R.; Willems, R.J.; Baquero, F.; Coque, T.M. Population biology of intestinal Enterococcus isolates from hospitalized and nonhospitalized individuals in different age groups. Appl. Environ. Microbiol. 2015, 81, 1820-1831. [CrossRef]

19. Tedim, A.P.; Ruíz-Garbajosa, P.; Rodríguez, M.C.; Rodríguez-Baños, M.; Lanza, V.F.; Derdoy, L.; Cárdenas Zurita, G.; Loza, E.; Cantón, R.; Baquero, F.; et al. Long-term clonal dynamics of Enterococcus faecium strains causing bloodstream infections (1995-2015) in Spain. J. Antimicrob. Chemother. 2017, 72, 48-55. [CrossRef]

20. Baquero, F.; Coque, T.M. Multilevel population genetics in antibiotic resistance. FEMS Microbiol. Rev. 2011, 35, 705-706. [CrossRef]

21. Instituto Nacional de Enfermedades Infecciosas. Protocolo De Trabajo Red WHONET Argentina; SERVICIO ANTIMICROBIANOS, Dpto. Bacteriología, Instituto Nacional de Enfermedades Infecciosas (INEI): Buenos Aires, Argentina, 2018.

22. Magiorakos, A.-P.; Srinivasan, A.; Carey, R.B.; Carmeli, Y.; Falagas, M.E.; Giske, C.G.; Harbarth, S.; Hindler, J.F.; Kahlmeter, G.; Olsson-Liljequist, B.; et al. Multidrug-resistant, extensively drug-resistant and pandrug-resistant bacteria: An international expert proposal for interim standard definitions for acquired resistance. Clin. Microbiol. Infect. 2012, 18, 268-281. [CrossRef]

23. Nallapareddy, S.R.; Duh, R.-W.; Singh, K.V.; Murray, B.E. Molecular typing of selected Enterococcus faecalis isolates: Pilot study using multilocus sequence typing and pulsed-field gel electrophoresis. J. Clin. Microbiol. 2002, 40, 868-876. [CrossRef] [PubMed] 
24. Hayakawa, K.; Marchaim, D.; Vidaillac, C.; Lephart, P.; Pogue, J.M.; Sunkara, B.; Kotra, H.; Hasan, A.; Shango, M.; Yerramalla, Y.; et al. Growing prevalence of vancomycin-resistant Enterococcus faecalis in the region with the highest prevalence of vancomycin-resistant Staphylococcus aureus. Infect. Control Hosp. Epidemiol. 2011, 32, 922-924. [CrossRef] [PubMed]

25. Gawryszewska, I.; Żabicka, D.; Bojarska, K.; Malinowska, K.; Hryniewicz, W.; Sadowy, E. Invasive enterococcal infections in Poland: The current epidemiological situation. Eur. J. Clin. Microbiol. Infect. Dis. 2016, 35, 847-856. [CrossRef] [PubMed]

26. Gagetti, P.; Bonofiglio, L.; García Gabarrot, G.; Kaufman, S.; Mollerach, M.; Vigliarolo, L.; von Specht, M.; Toresani, I.; Lopardo, H.A. Resistance to $\beta$-lactams in enterococci. Rev. Argent. Microbiol. 2019, 51, 179-183. [CrossRef]

27. Freitas, A.R.; Tedim, A.P.; Francia, M.V.; Jensen, L.B.; Novais, C.; Peixe, L.; Sánchez-Valenzuela, A.; Sundsfjord, A.; Hegstad, K.; Werner, G.; et al. Multilevel population genetic analysis of vanA and vanB Enterococcus faecium causing nosocomial outbreaks in 27 countries (1986-2012). J. Antimicrob. Chemother. 2016, 71, 3351-3366. [CrossRef]

28. Pourcel, G.; Sparo, M.; Corso, A.; Delpech, G.; Gagetti, P.; de Luca, M.M.; Bernstein, J.; Schell, C.; Lissarrague, S.; Basualdo, J.A. Molecular Genetic Profiling of Clinical and Foodborne Strains of Enterococci with High Level Resistance to Gentamicin and Vancomycin. Clin. Microbiol. Open Access 2017, 6, 1000272. [CrossRef]

29. Osuka, H.; Nakajima, J.; Oishi, T.; Funayama, Y.; Ebihara, T.; Ishikawa, H.; Saito, K.; Koganemaru, H.; Hitomi, S. High-level aminoglycoside resistance in Enterococcus faecalis and Enterococcus faecium causing invasive infection: Twelve-year surveillance in the Minami Ibaraki Area. J. Infect. Chemother. 2016, 22, 61-63. [CrossRef]

30. Rice, L.B.; Hutton-Thomas, R.; Lakticova, V.; Helfand, M.S.; Donskey, C.J. Beta-lactam antibiotics and gastrointestinal colonization with vancomycin-resistant enterococci. J. Infect. Dis. 2004, 189, 1113-1118. [CrossRef]

31. Facklam, R.R.; Collins, M.D. Identification of Enterococcus species isolated from human infections by a conventional test scheme. J. Clin. Microbiol. 1989, 27, 731-734. [CrossRef]

32. Clinical and Laboratory Standards Institute. Performance Standards for Antimicrobial Susceptibility Testing: Twenty-Seventh Informational Supplement M100; Clinical and Laboratory Standards Institute: Wayne, PA, USA, 2017; ISBN 1-56238-804-5.

33. McBride, S.M.; Fischetti, V.A.; Leblanc, D.J.; Moellering, R.C.; Gilmore, M.S. Genetic diversity among Enterococcus faecalis. PLoS ONE 2007, 2, e582. [CrossRef]

34. Aarestrup, F.M.; Agerso, Y.; Gerner-Smidt, P.; Madsen, M.; Jensen, L.B. Comparison of antimicrobial resistance phenotypes and resistance genes in Enterococcus faecalis and Enterococcus faecium from humans in the community, broilers, and pigs in Denmark. Diagn. Microbiol. Infect. Dis. 2000, 37, 127-137. [CrossRef]

35. Depardieu, F.; Perichon, B.; Courvalin, P. Detection of the van alphabet and identification of enterococci and staphylococci at the species level by multiplex PCR. J. Clin. Microbiol. 2004, 42, 5857-5860. [CrossRef] [PubMed]

36. Coque, T.M.; Willems, R.J.L.; Fortún, J.; Top, J.; Diz, S.; Loza, E.; Cantón, R.; Baquero, F. Population structure of Enterococcus faecium causing bacteremia in a Spanish university hospital: Setting the scene for a future increase in vancomycin resistance? Antimicrob. Agents Chemother. 2005, 49, 2693-2700. [CrossRef] [PubMed]

37. Tenover, F.C.; Arbeit, R.D.; Goering, R.V.; Mickelsen, P.A.; Murray, B.E.; Persing, D.H.; Swaminathan, B. Interpreting chromosomal DNA restriction patterns produced by pulsed-field gel electrophoresis: Criteria for bacterial strain typing. J. Clin. Microbiol. 1995, 33, 2233-2239. [CrossRef] [PubMed] 
38. Homan, W.L.; Tribe, D.; Poznanski, S.; Li, M.; Hogg, G.; Spalburg, E.; Van Embden, J.D.A.; Willems, R.J.L. Multilocus sequence typing scheme for Enterococcus faecium. J. Clin. Microbiol. 2002, 40, 1963-1971. [CrossRef] [PubMed]

39. Ruiz-Garbajosa, P.; Bonten, M.J.M.; Robinson, D.A.; Top, J.; Nallapareddy, S.R.; Torres, C.; Coque, T.M.; Cantón, R.; Baquero, F.; Murray, B.E.; et al. Multilocus sequence typing scheme for Enterococcus faecalis reveals hospital-adapted genetic complexes in a background of high rates of recombination. J. Clin. Microbiol. 2006, 44, 2220-2228. [CrossRef]

(C) 2020 by the authors. Licensee MDPI, Basel, Switzerland. This article is an open access article distributed under the terms and conditions of the Creative Commons Attribution (CC BY) license (http://creativecommons.org/licenses/by/4.0/). 